\title{
Motivational Strategies Using in College English Teahcing in China*
}

\author{
Juju Wang \\ School of Foreign Studies \\ QiLu Normal University \\ Jinan, China 250013
}

\begin{abstract}
This paper explores how to apply motivational theories in college English teaching on the base of the introduction of its psychological development from humanism, behaviorism to cognitivism. Different strategies specific to high and low proficiency students are also listed after with the hope that providing information for the college English learning practice.
\end{abstract}

Keywords-motivational strategies; college English teaching; impact

\section{INTRODUCTION}

Since 1990s, L2 motivation research has been switched from social-psychology to Education-oriented approach which advocated connecting the teaching environments in class with the influential elements in L2 motivation. The stimulating effects on students' learning motivation from the teacher became the focus abroad. While in China, college students' lack of English learning motivation has been the trouble, which is the main phenomenon on Chinese college English class. Many teachers' complains arose: college students are less interested in English learning; the students neither study English in class nor in their spare time; it has become impossible to teach English for non-English majors. The application of motivational strategies in college English class is worth exploring and studying.

For the sake of the significance of L2 learning, motivation has become the hot topic among the second language acquisition field since 1950s. Rest on Canadian psychologist Gardner and his colleagues, L2 motivation research mainly explored how the students' motivation was influenced by the social psychological variables like students attitude toward the second language, the second language speakers as well as the language's culture. L2 motivation model's Construction from the class teaching practice was stressed since the focus switched to the school education center, while the teacher's efforts on stimulating the students' motivation became outstanding too.

Demotivation exits in the L2 learning, which means that the specific external factors which are undercutting or reducing the progressing behavior's motivation defined by Dornyei. While with the deep study of demotivation, both

*It is a Phased achievement of the "Study on the Teaching Strategies for Undergraduates Based on Learning Style" of Shandong social sciences planning study program (16CZWJ55). internal and external factors are all included by the scholars. Lots of the researchers did extent investigations on demotivation in different schools, like Chambers, Rudnai, Oxford, Ushida, Dornyei, Keblawi from overseas, and Wang Tianfa, Liang Liang from abroad. All the results from the investigations showed us that most students considered it was teacher who was the main factor that reduced their learning motivation. Teacher cannot be neglected when we study the students' learning motivation process, which can promote the teacher to adjust the behavior, avoid the unbeneficial effects for the students, and stimulate and maintain the students' motivation better.

\section{INTRODUCTION OF MOTIVATION}

If a teacher quotes widely in class which is quite fascinating as well as entertaining, the students would enter the class early and participate warmly in the class. The students' behavior is obviously intrigued by some motivation. We'll start off by introducing its definition.

Covington once pointed out that motivation, like the earth gravity, was easy to describe but difficult to define. For quite a long time, many researchers tried to define motivation from different perspectives. Houston considered motivation was the factor that launches guides and influences the intensity and durability of some behavior (Houston, 1985). Pintrich and Shunk defined motivation as the internal psychological process that guided, stimulated and maintained by a goal (Pintrich, Shunk, 1996). Williams and Burden interpreted motivation as cognitive and affective stimulating, decision which promotes someone to make conscious behavior and endeavor to make physical and mental efforts in order to achieve planned objective (Williams, Burden, 1997).

All the above definitions show us their common characters with some distinctions. Most scholars agreed with motivation have something with people's behavior: choosing specific decision and making efforts with certain consistency.

\section{A. Motivation Theory in Behaviorism and Humanism}

Motivation theory has developed from behaviorism, humanism to cognitivism. It was influenced by the psychological behaviorism and emerged as instinct theory, drive theory and stimulus-response theory. As the 
representative of instinct theory, James and Mcdougall considered people's behavior is directed by their instinct which is the basic drive in all human behaviors. Instinct theory exerted great influence at the beginning of the 20's century and as the dominate position which replaced by drive theory latter which was put forward by American psychologist Hull in 1943. Hull once internal drive would be generated once someone's need cannot be satisfied. While the need is satisfied, the internal drive will reduced and even quieted down. After that, psychologist of behaviorism began to study how to build and maintain the behavior system through intensifying mechanism instead of satisfying instinct and drive. Stimulate- response theory was put forward by Skinner in 1957, which stressed the impact of intensification and pointed that any behavior will be intensified through positive awards, otherwise it will disappear.

After the middle of 20's century, psychologist of humanism like Rogers and Maslow challenged behaviorists' theory built on experiments on animals, and devoted to study human's motivation. Maslow divided humans' needs into 5 levels which listed from lowest to the top like: physical needs (like thirsty, hanger, sleep etc.); safety needs (like getting rid of danger, scare or threaten etc.); feeling needs (like kinship, love, friendship etc.); respecting needs (like confidence, self- respect, prestige etc.); self-realizing needs (developing once ideal and value to the greatest extent).

\section{B. Motivation Theory of Cognitivism}

In the latest 3 decades, motivation theory began to draw on how individual's behavior is influenced by cognitive elements: people's attitude, ideas, concepts and understanding of other things. The most influential theories were expectancy value theories, goal theories, selfdetermination theories, and theory of planned behavior. Each theory focused on different elements but all agreed on that individual's cognitive course directly leads to emerge of the motivation. It is necessary to integrate different theories and explore motivation theory's guiding significance in class teaching.

\section{PSYCHOLOGICAL MOTIVATION THEORIES' IMPACT ON EDUCATION}

Intensifying theory is used most commonly in classroom teaching, and teachers will stimulate students through oral praise or physical praise like giving higher score consciously or unconsciously. Most teachers believe praise is the most direct and efficient way to intensify learning motivation. Researchers did lots of research in praise's impact on education, which turned out that the results were quite different. Some found the positive effects of the praise which can boost students' learning efficiency and the extent of participation in the learning tasks (Gambrell \& Marinak, 1997). Yet others found praise's influence was exaggerated, and students' attention was switched from learning task to the award, which would result into decline of the score (Heckhausen, 1991). In fact, it is crucial that how to use the praise positively and reasonably. In second language teaching, teachers should be wary that the extent and frequency of praise using should be controlled avoiding excessive using which would enable the students to be over concerned with the praise and make award earning be the object of their study. Teachers should always remember that praise's aim is to stimulate and maintain students' learning motivation. Therefore, students' efforts and achievement should be taken into consideration besides the final learning results.

According to Maslow's needs level, physical and safety needs are the basic ones for human. The negative feeling like Anxiety and scare should be firstly removed, and psychological safety could make it possible to truly devote into study. Once the safety needs been met, learners will pursue higher need like feeling and respect needs. In the class relaxing and democratic studying atmosphere should be built by the teacher, which inquire human tunes when he talking and students effort and achievement should be pointed out while over strict criticizing should be avoided. Teachers should notice the change of students' mood in order to adjust the teaching mode.

Expectancy value theories also inspired teaching. Success is expected by most people, and second language learners are no exception. The expecting for success and the possibility of success is the core factor that influences the second language learning motivation. If learners are aware that effort and achievement are positive correlated or success is in their own hands rather than limited with external uncontrollable elements, they would make lasting and enduring efforts. In case of the success is achieved, learners self-efficacy will be promoted, which in turn will improve their learning enthusiasm. Second language's value endowed by the learners will affect their motivation. Only they believe one learning task is significant and useful, could they truly participate. So the learning tasks' difficulty should be controlled by the teacher so that they can acquire the feeling of success. At the same time, the objective of the task should be integrated with the students' interests, and the contents connected with the students could be added into the task. Frequent encourage and learning strategy training could improve students' confidence and self-efficacy. Before task illustration, the usage and meaning of a task should be clarified with the method and procedure of how to accomplish.

\section{STIMULATING DifFERENT STUDENTS EFFICIENTLY}

In order to most efficiently take advantage of motivational strategies, teachers should take different requirements of different students into consideration. Even in one class, students' English proficiency is quite different. "Middle group" is commonly focused by the teacher, while high proficiency and low proficiency students are often neglected. In fact, this two kinds of students need more teachers encourage. Low proficiency students are quite easy to frustrate and lose interest in English learning; therefore they need to rebuild confidence and interest in English learning. High proficiency students' expectation and need for teachers' teaching is higher too. Their learning initiative would be undercut, if their needs were unsatisfied. It is a challenge for the teacher to stimulate high and low 
proficiency students' interest aiming at exploit their potentiality and achieve good learning results.

\section{A. Motivational Strategies for Low Proficiency Students}

Teachers hardly draw attention on the low proficiency students in class, so they will feel more negatively. The conscious and unconscious performances by the teacher mainly are: they are scarcely questioned or given few time to think when questioned; few communication with them without concern with their idea; hardly praise or encourage them and without learning judgments or feedback etc. through above mentioned behaviors are reluctant, they can illustrate that teachers may give the students up who mostly need concern and encourage.

Butkowsky and Willows found that low proficiency students often have following psychological tendency: the original expectation for success is low; giving up immediately confronting difficulties; attributing their failure to lack of ability rather than the uncontrollable elements like improper methods or less efforts; attributing their success to uncontrollable elements like luck or easy task rather than own ability or efforts; expectation for success will drop sharply. Teacher should be informed with all the psychological factors affecting low proficiency students, and make corresponding motivational strategies.

1) Promoting confidence and success expectation: Low proficiency students could sit in the front or the middle of the classroom so that they can be encouraged by teachers' frequent smile and eye-contacts. Simple questions are suitable for them who can be guided to supplement or modify their answers. Each students endeavor and achievement should be praised openly and sincerely, and their improvement parts should be pointed out too. Providing teacher's contact means like telephone number or email to them so that they can contact the teacher anytime they have a question.

Language learning without authentic circumstances is a quite long process, during which the students will unavoidably confront many difficulties and obstacles. Teachers can help them to realize the objectiveness of the difficulties which can conquer through their endeavor. Because of the personal difference, each student may have their own weakness which should be paid attention to and try to figure out some strategies to guide.

Setting learning objectives can let the students clarify their direction, but too general and out-reached one may let them lose confidence and slip into helpless and desperation. Objectives for low proficiency can be flexible with specific time tables.

2) Entertaining English learning and promoting students' interests: Class is the main place for students' learning, which should be created into a positive, attracting learning community. Relaxing and joyous atmosphere can lower or eliminate students' anxiety. The rhythm of the class should be flexible too, and some easy activities can be arranged after some high tension ones.
Textbook staff may let the students feel boring, and more other materials can be added into the class. For the low proficiency students, some feasible methods are listed: interview or personal communication; group work or brain storming; topic mentioned composition; open-ended questions etc.

\section{B. Motivational Strategies for High Proficiency Students}

Teachers often regard high proficiency students as selfconscious and with strong learning motivation. However, learning motivation is a dynamic variable like a growing plants may wither without sunshine and raindrops. Maintaining motivation is as important as stimulating one.

1) Integrating Culture and Providing Cultural Experience: The cultural nature of language determines that language teaching should consist of cultural dimension which contains of content dimension, context dimension, and poetic dimension. High proficiency students have had profound vocabulary and grammar as well as sound listening, speaking, reading and writing skills. Under such condition, it is necessary to integrate cultural elements into class and promote students cultural appreciating and crosscultural communication abilities.

In 1993, Domoney and Harris pointed out that introducing popular culture is one of the significant, relaxing and collaborative class tasks. With the development of modern technologies and open-up policy, the young have more excesses to western culture which have changed young people's life style and values. Introducing the popular staff into the college English class can refresh the atmosphere and boost the learning motivation.

2) Promoting Self-stimulating System: Today's foreign language education is student-centered with self-studying concepts. Under this context, teachers should not only study how to stimulate students but also how to help them selfstimulate.

Dornyei listed five self-stimulating strategies: commitment control strategies; metacognitive control strategies; satiation control strategies; emotion control strategies; environmental control strategies. Teachers can show the students different strategies and let them find the most suitable one.

\section{CONCLUSION}

Motivational theories in psychological and second language learning field were analyzed in this paper. It developed through behaviorism stimulate-response theory to humanism requirement levels theory and finally the cognitive theories. All of these had deep impact on the second language teaching.

Chinese current situation determines that in college English teaching, low and high proficiency students are often neglected by the teacher. For the sack of these, the author puts forward distinct strategies in order to stimulate the students to the largest extent boost teacher students' 
communication and try to find more opportunities for college English teaching.

\section{REFERENCES}

[1] Gambrell, Marinak, Motivating readers through integrated instruction [C]. Newark: International Reading Association, 1997.

[2] Harmer, The practice of English education [M]. New York: Palgrave Macmillan, 1991.

[3] Houston, Motivation [M]. New York: Macmillan Publishing Company, 1985.

[4] Pintrich, Motivation in education: theory, research and applications [M]. Needhan Heights, MA: Allyn and Bacon, 1996.

[5] William, Burden, Ssychology for Language Teachers [M]. Cambridge: Cambridge University Press, 1997. 